\title{
Consciência ou segurança? Questões de gênero num processo seletivo interno
}

\author{
LUIZA WANKe Freitas ${ }^{1}$ \\ VIVIAN LUIZ COCO $^{1}$ \\ LUCIA BARBOSA DE OLIVEIRA ${ }^{2}$ \\ ana Christina Celano Teixeira ${ }^{1}$ \\ ${ }^{1}$ FACULDADES IBMEC, RIO DE JANEIRO - RJ, BRASIL \\ 2 Fundação Getulio Vargas (FGV EBAPE) / Escola Brasileira de AdMinistração Pública e de EMPreSAS, Rio de Janeiro - RJ, BRASIL
}

\section{Resumo}

O caso aborda a situação vivenciada por Gustavo, gestor de uma equipe de seis analistas da diretoria financeira de um grande banco público. Um dos analistas seniores da equipe havia sido promovido a gerente de outra área e ele se viu diante da necessidade de escolher um dos analistas plenos de sua equipe para o cargo. Analisadas as competências e o perfil dos candidatos, Gustavo tinha a convicção que Clarice era a mais preparada para assumir a vaga. Ao mesmo tempo, ele sabia que Clarice poderia engravidar em um futuro próximo e, se isso ocorresse, por uma condição médica especial, ela passaria um ano ausente, somadas as licenças saúde e maternidade. Gustavo se vê, portanto, diante de um dilema. Deveria ele levar em conta apenas as habilidades da candidata, ou seria também necessário considerar a repercussão entre os demais colegas e o impacto sobre o trabalho de toda a equipe caso ela engravidasse logo após a promoção?

Palavras-chave: Recrutamento e seleção. Gênero. Liderança. Diversidade. Teto de vidro.

\section{Consciousness or safety? Gender issues in an internal selection process}

\section{Abstract}

The case addresses the situation experienced by Gustavo, manager of a team of six analysts in the financial department of a large public bank. One of the team's senior analysts had been promoted to manager in another area, and he was faced with the need to choose one of his team's full analysts for the position. After analyzing the candidates' skills and profile, Gustavo was convinced that Clarice was the most prepared to take the job. At the same time, he knew that Clarice could become pregnant in the near future and, if that happened, due to a special medical condition, she would be absent for a year, including sick and maternity leave. Gustavo is therefore faced with a dilemma. Should he take into account only the candidate's skills, or would it also be necessary to consider the repercussion among the other colleagues and the impact on the work of the entire team if she became pregnant soon after the promotion?

Keywords: Recruitment and selection. Gender. Leadership. Diversity. Glass ceiling.

\section{¿Conciencia o seguridad? Cuestiones de género en un proceso de selección interno}

\section{Resumen}

El caso aborda la situación vivida por Gustavo, gerente de un equipo de seis analistas de la dirección financiera de un gran banco público. Uno de los analistas senior del equipo fue ascendido a gerente de otra área y Gustavo necesitó elegir a uno de los analistas plenos de su equipo para suplir la vacante. Tras analizar las habilidades y el perfil de los candidatos, se convenció de que Clarice era la más preparada para asumir el puesto. Al mismo tiempo, sabía que ella podría quedar embarazada en un futuro cercano y, si eso sucediese, debido a una condición médica especial, estaría ausente durante un año -sumadas las licencias de salud y maternidad -. Por lo tanto, Gustavo se encontró ante un dilema. ¿Debería tener en cuenta solo las habilidades de la candidata, o también sería necesario considerar la repercusión entre los demás compañeros y el impacto en el trabajo de todo el equipo si ella quedara embarazada poco después del ascenso laboral?

Palabras clave: Reclutamiento y selección. Género. Liderazgo. Diversidad. Techo de cristal. 


\section{INTRODUÇÃO}

Em um dia que parecia como outro qualquer, Gustavo, um executivo experiente do setor bancário, com 50 anos de idade e 30 de carreira, preparava-se para almoçar com Abigail, uma querida colega de trabalho. Ele andava preocupado em como resolver uma questão a respeito de uma vaga que acabara de abrir em sua área e que resultaria na promoção de um dos membros de sua equipe. Dentre as três opções de analistas que seriam elegíveis para a nova posição, um nome lhe parecia o mais indicado: Clarice. No entanto, esta poderia não ser uma decisão tão fácil.

Gustavo e Abigail eram amigos há quase 10 anos e conversavam sobre tudo. Logo que se sentaram à mesa do restaurante que costumavam frequentar, ele começou a conversa contando que sua filha estava grávida e o quanto estava feliz com a chegada de sua primeira netinha. $\mathrm{O}$ que fez Abigail lembrar de contar que havia estado no final de semana anterior com Clarice, uma das analistas que fazia parte da equipe de Gustavo.

Ele imediatamente perguntou como ela estava, pois Clarice havia recentemente perdido um bebê já com seis meses de gravidez. Uma história muito triste, que mexeu bastante com ele e toda a equipe. Abigail contou que Clarice estava um pouco melhor, pois sua médica havia concluído o diagnóstico sobre o que levou à perda do bebê, indicando que uma próxima gravidez seria possível, desde que tomados os cuidados necessários para evitar uma nova ocorrência.

Gustavo ficou muito feliz em saber que Clarice estava mais tranquila e logo se interessou por perguntar sobre o diagnóstico. Abigail explicou que era uma condição no colo do útero e que Clarice poderia ter outro bebê, desde que fizesse um procedimento cirúrgico no início da gravidez e permanecesse em repouso até o nascimento. Tentando disfarçar, Gustavo sentiu um frio na barriga ao pensar nos seus planos de nomear Clarice para a posição de analista sênior que acabara de ficar vaga. Ele se questionava sobre o fato de estar no ano de 2019 não tornar essa decisão mais fácil para um gestor.

\section{Gustavo}

Gustavo era carioca e, em 1989, aos 20 anos, passou no concurso para escriturário de um grande banco público. O concurso era nacional e ele foi convocado para tomar posse em uma agência pequena, no interior do Rio Grande do Sul. Lá foi ele, com sua namorada, que rapidamente virou noiva e depois esposa. Ali Gustavo começou a construir sua vida e sua carreira. Depois de cinco anos de empresa, um tempo relativamente curto, chegou ao cargo de gerente de contas e conseguiu voltar para o Rio de Janeiro. Nesse mesmo momento, em 1994, nascia sua filha.

Funcionário muito dedicado, galgou cargos aos poucos, dentro das perspectivas que a empresa oferecia e que estavam muito ligadas ao tempo de serviço. Gustavo trabalhou em diversas agências e também em diferentes áreas operacionais até que, com 15 anos de carreira, passou em uma seleção para trabalhar como analista júnior da diretoria financeira do banco.

Na diretoria, dedicou-se especialmente aos produtos financeiros, o que o tornou experiente no assunto e admirado por tal experiência. Dois anos depois, foi promovido a analista pleno e, nos três anos que se seguiram, a analista sênior. Gustavo era frequentemente reconhecido por seus superiores pela qualidade técnica do seu trabalho e por sua dedicação. Dentre seus colegas, era reconhecido como a pessoa que agregava todos em prol do trabalho e que ajudava na manutenção de um ótimo ambiente.

Diante de todos os feedbacks recebidos, Gustavo já se sentia preparado para assumir o cargo de gerente. Após ser preterido em algumas ocasiões e depois de oito anos como analista sênior, a oportunidade surgiu com uma grande reestruturação na diretoria. Gustavo foi finalmente nomeado gerente.

Sua equipe era composta de seis analistas - três plenos e três seniores. Gustavo era um gerente extremamente acolhedor e cuidava da sua equipe com atenção e carinho. Sempre atento às necessidades pessoais de cada um, conhecia suas histórias e estava disposto a ajudar a todos. Por ser profundo conhecedor dos aspectos técnicos do trabalho, gerenciava de perto a execução, garantindo o ótimo desempenho das atividades da equipe.

Em alguns momentos esse aspecto muito humano e acolhedor de Gustavo gerava-Ihe alguma dificuldade em dar feedbacks negativos ou cobrar resultados melhores dos funcionários que tinham desempenho aquém do esperado. No dia a dia, repassava as atividades mais complexas aos funcionários mais habilidosos, o que acabava por deixar menos atividades para aqueles com pior desempenho. 
Em 2019, quando completou 50 anos de idade e 30 anos de carreira, sendo dois deles como gerente dessa equipe, Gustavo começou a planejar sua aposentadoria. Em pouco tempo estaria dedicando-se exclusivamente à família e à neta que estava a caminho.

\section{A organização e o ambiente interno}

O banco onde Gustavo trabalhava era público e de grande porte, com mais de 70 mil funcionários e agências pulverizadas por todo o Brasil. Na época em que Gustavo iniciou sua carreira, a organização já contava com mais de 100 anos de história e era muito conservadora, com uma cultura bastante forte. O clima organizacional era acolhedor e os funcionários consideravam os colegas quase como membros da família, tamanha era a ligação entre eles. Naquela época, a ascensão estava ligada ao tempo de carreira e quase não se viam mulheres nos cargos de gestão.

Com o passar do tempo, a cultura foi mudando e, aos poucos, as promoções tornaram-se mais motivadas pela avaliação das habilidades e competências dos funcionários. Foi implantado no banco um sistema de apoio aos processos seletivos internos, no qual os funcionários cadastravam sua formação, incluindo cursos de especialização, além de cargos exercidos e resultados das últimas avaliações de desempenho. 0 sistema era normalmente utilizado no início dos processos e ranqueava os funcionários de acordo com a pontuação obtida considerando os quesitos parametrizados por cada gestor. A partir daí, os processos de seleção seguiam normalmente com outras etapas, como entrevistas ou dinâmicas de grupo.

A diretoria financeira localizava-se no Rio de Janeiro e tinha cerca de 300 funcionários; dentre os quais, 50 gestores e 250 analistas - 100 juniores, 90 plenos e 60 seniores. No grupo de gestores, havia apenas duas mulheres. Nas funções técnicas, o equilíbrio de gênero era maior: $45 \%$ dos cargos eram ocupados por mulheres.

Normalmente a diretoria utilizava o sistema de apoio nos processos seletivos para analista júnior, escolhendo os funcionários mais bem pontuados de outras áreas. No caso de processos seletivos para as demais funções, a maioria dos gestores optava por promover funcionários de suas próprias equipes.

\section{A seleção para analista sênior}

Um analista sênior da equipe gerenciada por Gustavo acabara de ser promovido a gerente de outra equipe por meio de um processo seletivo interno. A diretoria deu a Gustavo a autonomia para escolher quem seria nomeado para o cargo recém-aberto. Apesar da existência do sistema para seleção interna, Gustavo optou por não recorrer a ele, pois considerava que sua avaliação direta como gestor no dia a dia era mais importante do que a pontuação calculada pelo sistema.

Ana Beatriz era a analista pleno mais antiga, tinha 45 anos de idade, 25 anos de empresa e já estava há 8 anos no cargo. O executivo da área, chefe de Gustavo, apoiava sua nomeação, porque considerava que o tempo de casa era um fator importante nas decisões relativas a promoções. No entanto, Gustavo considerava o desempenho da funcionária aquém do desejável para um analista sênior, pois Ihe faltava proatividade e iniciativa. No dia a dia, Gustavo precisava cobrar diversas vezes cada atividade que era atribuída a Ana Beatriz e, por vezes, precisava intervir para solucionar problemas mais complexos.

Paulo era outro analista pleno da equipe de Gustavo. Tinha 32 anos de idade, 8 de empresa e há pouco mais de um ano havia sido promovido a analista pleno. Durante esse curto período, Gustavo percebeu bastante potencial em Paulo, um profissional inteligente, que demonstrava bom domínio dos aspectos técnicos do trabalho. Ainda assim, Gustavo se sentia inseguro quanto às habilidades comportamentais de Paulo. Teria ele o equilíbrio e a dedicação que se espera de alguém comprometido com a equipe e a organização? Em algumas interações desde que entrou na equipe, Gustavo percebeu que faltava interesse e iniciativa por parte de Paulo na solução das demandas da área.

Clarice era a terceira analista pleno da equipe. Tinha 28 anos de idade, 8 de empresa e 2 como analista pleno. Sua história recente era marcada por um fato dramático. Há alguns meses perdeu seu bebê com seis meses de gravidez. Nasceu com vida, mas faleceu uma hora após o parto, o que a levou a gozar de licença maternidade compulsória. Clarice chegou a recorrer a todos os órgãos de gestão de pessoas da empresa para abrir mão de sua licença maternidade sem lograr êxito. Naquele momento, faltavam duas semanas para seu retorno ao trabalho. 
Apesar de Clarice estar há somente dois anos na equipe, Gustavo a considerava pronta para a posição de analista sênior. Costumava confiar-Ihe os problemas mais complexos, e ela os resolvia com rapidez e qualidade. Além disso, estava sempre interessada em aprender e colaborar com a equipe.

O almoço com a amiga Abigail aconteceu exatamente durante o processo de análise e definição da promoção interna da equipe. Naquela conversa informal, Abigail revelou a Gustavo que, em uma conversa, Clarice confidenciou-Ihe que sua obstetra havia concluído o diagnóstico sobre o que levou à perda do bebê. O problema de Clarice levaria a necessidade de uma intervenção cirúrgica e repouso total em caso de uma futura gravidez, o que prolongaria ainda mais sua ausência por licença saúde e maternidade futuramente.

Gustavo voltou do almoço desnorteado. Estava certo de que Clarice era o nome certo para o cargo, mas essa nova informação trouxe muitas dúvidas. Se ele nomeasse Clarice e ela engravidasse em seguida, teria de gerir a equipe durante um ano com um analista sênior a menos. E, ainda por cima, teria de lidar com a frustração de Ana Beatriz.

Se optasse por nomear Ana Beatriz para analista sênior, sabia que seu desempenho poderia comprometer as atividades da equipe. Ainda que fosse mais experiente, Gustavo não confiava no trabalho da analista. E pensava que seria injusto promovê-la sem que fosse, em sua opinião, a mais competente. De forma análoga, acreditava que também seria injusto promover Paulo, dado que estaria recompensando uma pessoa com atitudes questionáveis. Tanto a nomeação do novato quanto a de Ana Beatriz evitariam muitos problemas caso Clarice fosse a escolhida e optasse por engravidar novamente. 0 que fazer? 


\section{NOTAS DE ENSINO}

\section{Objetivos de ensino}

Com base na leitura e análise do caso de ensino proposto, é possível abordar e refletir sobre temas relacionados à gestão de recursos humanos e ao comportamento organizacional, com destaque para:

- recrutamento e seleção de pessoas;

- liderança de equipes;

- diversidade e inclusão/discriminação de gênero nas organizações.

Espera-se, ainda, que a discussão deste caso permita aos estudantes:

- exercitar o pensamento crítico em situações que envolvem escolhas entre alternativas excludentes;

- refletir a respeito de um problema por diferentes ângulos e pontos de vista;

- discutir e analisar um dilema ético, posicionando-se com clareza.

\section{Fontes e métodos de coleta}

Os dados que permitiram o desenvolvimento deste caso foram obtidos por meio da experiência pessoal de uma das autoras e também de documentos públicos da organização em questão. Os nomes de todos os envolvidos foram alterados para preservar seu anonimato.

\section{Disciplinas sugeridas para uso do caso}

O caso de ensino destina-se a cursos de graduação e de pós-graduação da área da Administração, particularmente em disciplinas como Gestão de Recursos Humanos, Comportamento Organizacional e Liderança, ou outra cuja temática envolva questões ligadas à diversidade e à discriminação de gênero nas organizações.

\section{Possíveis tarefas a propor aos alunos}

A situação vivenciada por Gustavo permite a discussão de várias questões relativas à gestão de pessoas. Em primeiro lugar, os alunos e alunas podem ser estimulados a expor suas experiências relativas a processos seletivos de que fizeram parte tanto internos quanto externos. É possível que surjam entre as mulheres exemplos de processos de seleção ou promoção em que se sentiram preteridas relativamente aos homens.

Além dessa primeira troca de experiências, as seguintes questões podem ser propostas como forma de estimular o debate:

1. Como você classificaria o estilo de liderança de Gustavo? E o perfil de seus liderados?

2. Quais fatores devem ser levados em consideração num processo seletivo interno?

3. Você acredita que mulheres são ou podem ser discriminadas em processos seletivos? Explique.

4. Como você explicaria o fato de que as mulheres são minoria nos escalões superiores das organizações?

5. Quais benefícios uma organização pode ter ao promover a equidade de gênero nos níveis hierárquicos superiores?

6. Quem você promoveria a analista sênior se estivesse na posição de Gustavo? Justifique sua resposta.

A primeira questão permite a discussão sobre o tema da liderança, com foco no estilo de liderança de Gustavo. Este debate pode ser embasado conceitualmente na teoria situacional de Hersey e Blanchard (Blanchard, 2012) ou no modelo proposto por Goleman (2000), ambos discutidos em maior profundidade no referencial teórico. De forma complementar, pode-se discutir o perfil dos integrantes da equipe de Gustavo apresentados no caso - Clarice, Ana Beatriz e Paulo -, também com base na teoria situacional de Hersey e Blanchard (Blanchard, 2012). 
Na segunda questão, discute-se o processo de seleção interna para o cargo de analista sênior. Aqui, o professor pode abordar conceitualmente cada uma das etapas de um processo seletivo, com destaque para os conhecimentos, habilidades e atitudes necessários ao trabalho e os métodos de avaliação dos candidatos à posição. Em seguida, o professor pode estimular o debate em torno de outros tópicos relacionados a processos seletivos internos, incluindo: o papel da senioridade nas decisões sobre promoções, o estímulo à diversidade (de gênero e outras) e, ainda, a questão de capacidade atual versus potencial futuro.

A terceira pergunta permite o aprofundamento do problema do teto de vidro nas organizações, definido como barreiras reais, mas por vezes imperceptíveis, enfrentadas por mulheres no seu acesso a posições mais elevadas na hierarquia das organizações (Eagly \& Carli, 2007; Steil, 1997). Na situação relatada no caso, a analista Clarice pode perder sua chance de ser promovida em razão de uma possível gravidez.

Dando prosseguimento ao debate, e com referência à quarta questão, o professor pode exibir dados com o percentual de homens e mulheres em cargos de liderança nas organizações e, em seguida, pedir aos alunos e alunas que reflitam sobre as causas deste fenômeno. Na questão cinco, o professor pode fechar o debate iniciado na terceira questão estimulando a reflexão entre os estudantes a respeito das vantagens da diversidade, não apenas em relação ao gênero, mas incluindo outras dimensões como raça e etnia, orientação sexual e habilidades físicas e mentais.

Na sexta e última questão, os alunos devem se posicionar sobre a escolha do profissional mais adequado para assumir a posição de analista sênior, considerando as informações apresentadas no caso.

\section{Roteiro sugerido para aplicação do caso}

A aplicação do caso pode ser realizada antes ou depois da exposição das teorias e conceitos a serem trabalhados. Caso a etapa conceitual ocorra antes da discussão do caso, é importante que os alunos leiam com antecedência o material indicado, permitindo que tenham o embasamento teórico necessário para a discussão dos temas propostos.

A leitura do caso, estimada em aproximadamente 20 minutos, pode ser feita em sala de aula ou em casa, previamente à aula. Após a leitura, propõe-se que seja feita uma análise inicial do caso, com a identificação do dilema proposto. Esta atividade pode ser estimulada pelo professor por meio de perguntas como: qual o dilema em que Gustavo se encontra? Quem são as personagens principais e seus papéis neste dilema?

Após essa primeira análise, que pode ser feita em plenária, com todos os participantes, sugere-se a divisão da turma em grupos de três a cinco alunos, para que sejam discutidas as questões aqui propostas ou outras que o professor considere relevantes ao tema da aula. Em virtude da quantidade de perguntas, o professor pode conceder entre 20 e 40 minutos para os grupos discuti-las. Em seguida, a turma se reuniria novamente em plenária para o debate das perguntas e consolidação das respostas com a contribuição de todos.

Dependendo do nível de conhecimento da turma acerca do referencial teórico, o professor pode realizar uma breve exposição dos conceitos centrais do caso relacionados a seleção interna e promoção de empregados, perfis de liderança e/ou questão da diversidade de gênero nas organizações.

Na última questão, relacionada à decisão de Gustavo, o professor tem a opção de aplicar a técnica de debate, dividindo a turma em três grupos, para que cada um defenda, respectivamente, a promoção de Ana Beatriz, Clarice e Paulo. Seria concedido um tempo de 20 minutos para cada grupo consolidar seus argumentos. Cada grupo escolheria um debatedor e o professor conduziria o debate, com 5 minutos para cada um apresentar seus argumentos. Depois mais 5 minutos para réplica e tréplica dos dois lados.

Recomenda-se ainda que o professor faça uma pesquisa antes e depois da discussão (usando aplicativos como google forms, kahoot, mentimeter ou similares), visando avaliar o percentual de alunos que escolheu cada um dos três candidatos à promoção e, ainda, se houve mudanças de opinião diante dos argumentos apresentados pelos grupos. Para finalizar a aula, o professor pode apresentar o resultado das duas pesquisas, fazer uma conexão com as teorias trabalhadas e, em seguida, relatar o desfecho do caso real para os alunos. 


\section{Encerramento do caso}

No caso real, Gustavo chamou Clarice para conversar e compartilhou com ela o dilema em que se encontrava. Explicou que tinha a intenção de nomeá-la quando soube por Abigail sobre seu problema de saúde. Apesar de ter convicção de que Clarice possuía as habilidades necessárias para o cargo, tinha receio sobre sua nomeação, pois, caso engravidasse logo após assumir, Gustavo teria de lidar com o acúmulo de trabalho e com a possível revolta de Ana Beatriz.

Depois dessa explicação, Gustavo apresentou a Clarice a seguinte proposta: estaria disposto a nomeá-la, desde que ela passasse pelo menos um ano sem engravidar. Clarice aceitou a proposta e foi nomeada analista sênior da equipe.

\section{REFERENCIAL TEÓRICO}

Para contribuir com o embasamento teórico das questões para discussão, foi elaborada uma breve revisão da literatura sobre os temas liderança, recrutamento e seleção, e diversidade de gênero nas organizações, com destaque para o fenômeno do teto de vidro.

\section{Liderança}

Nas áreas de gestão e comportamento organizacional, a temática da liderança tem sido amplamente discutida. Muitas são as definições encontradas para o conceito de liderança, assim como teorias para explicá-la em toda sua complexidade. Segundo Yukl (2013), a maior parte das definições envolve a ideia de um processo em que uma pessoa exerce influência sobre outras com o objetivo de direcionar as atividades de um grupo ou organização. $O$ autor também apresenta sua própria definição.

Liderança é o processo de influenciar outras pessoas a entender e concordar sobre o que precisa ser feito e como fazê-lo, e o processo de facilitar os esforços individuais e coletivos para alcançar objetivos compartilhados (Yukl, 2013, p. 23, tradução nossa).

Com relação às teorias de liderança, é possível organizá-las em três grupos (Robbins, Judge \& Sobral, 2011). O primeiro envolve aquelas que tinham como foco as características pessoais ou traços de personalidade dos líderes. No segundo, estão as teorias comportamentais, que procuraram investigar em que medida a eficácia do líder dependeria mais de seu comportamento do que de características pessoais. Por fim, mais recentemente emergiram as teorias contingenciais de liderança, cuja proposição essencial é a de que a eficácia do líder estaria relacionada à sua capacidade de adequar seu estilo de liderança à situação em que se encontra (Robbins et al., 2011; Yukl, 2013).

No âmbito das teorias contingenciais, diversos pesquisadores propuseram modelos próprios levando em conta diferentes aspectos da situação, incluindo o ambiente organizacional, a natureza do trabalho, o perfil e a motivação dos liderados, a qualidade da relação do líder com seus liderados, o grau de cooperação entre os membros da equipe, além do perfil do próprio líder (Robbins et al., 2011; Yukl, 2013).

Deste conjunto, pode-se destacar a teoria da liderança situacional de Hersey e Blanchard, segundo a qual o líder precisaria adequar seu estilo de liderança ao perfil dos liderados, com destaque para suas competências e motivações (Blanchard, 2012; Yukl, 2013). Segundo a teoria, os liderados podem ser enquadrados em quatro estágios de desenvolvimento, denominados principiante empolgado (D1 - baixa competência, alto empenho); aprendiz decepcionado (D2 - baixa/alguma competência, baixo empenho); colaborador capaz, mas cauteloso (D3 - competência de moderada a alta, empenho variável); e realizador autoconfiante (D4 - alta competência, alto empenho). Dependendo do estágio de desenvolvimento do liderado, recomenda-se que o líder adote o estilo correspondente: E1 - direção; E2 - coaching; E3 - apoio; E4 - delegação (Blanchard, 2012). Cada um desses estilos envolve uma combinação entre comportamento de apoio e comportamento diretivo, conforme ilustrado na Figura 1. 
Figura 1

Modelo de liderança situacional

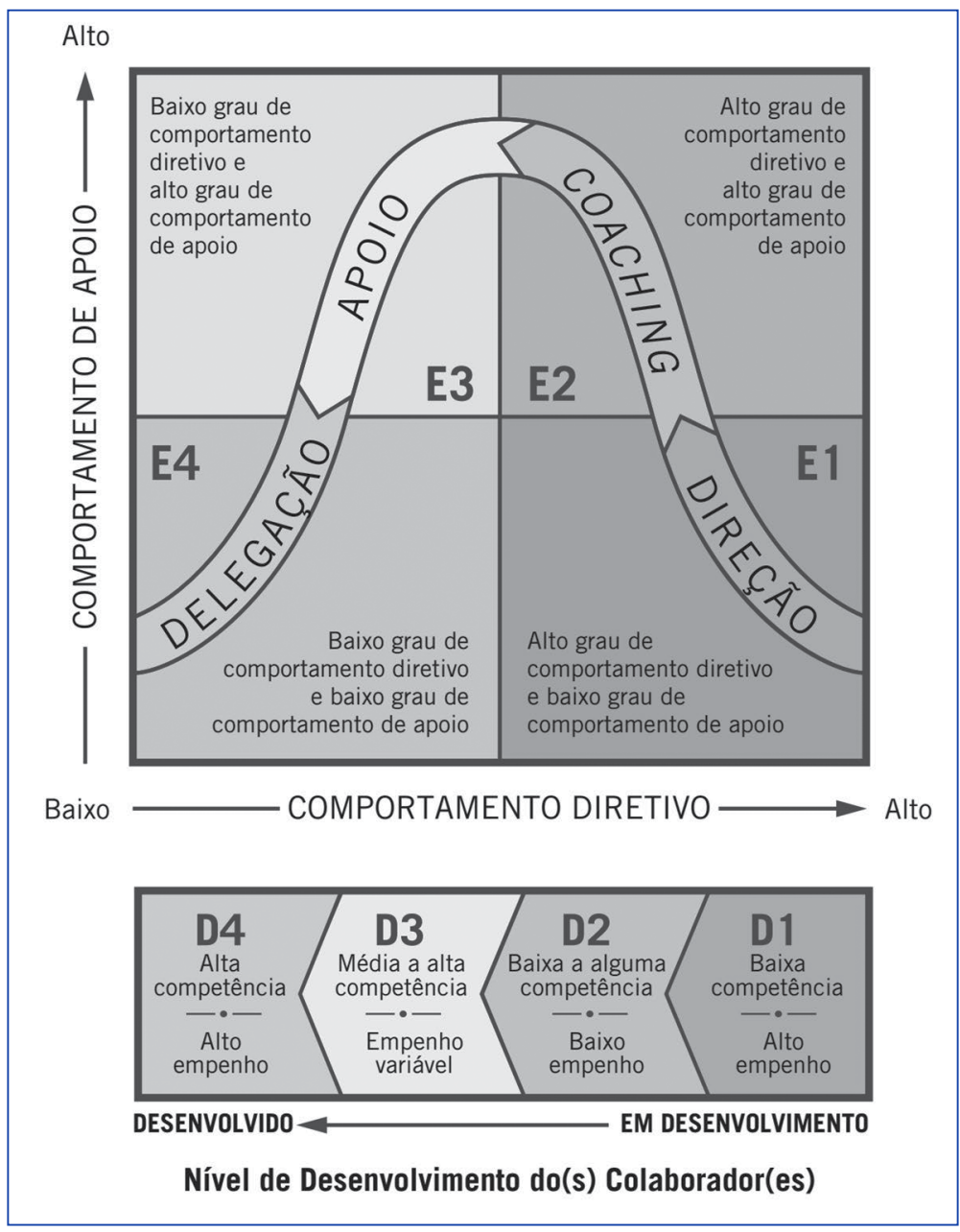

Fonte: Blanchard (2012, p. 75).

Dessa forma, para ser eficaz, o líder precisaria ser capaz de identificar o nível de desenvolvimento de cada um de seus liderados e, ainda, ter flexibilidade para adequar seu estilo de gestão aos respectivos níveis.

Por meio de pesquisas empíricas com um amplo conjunto de líderes em todo o mundo, Goleman (2000) propôs outro modelo contingencial, composto por seis estilos de liderança, conforme exposto no Quadro 1. Como pode ser observado, cada estilo seria mais adequado a determinadas situações e repercutiria de forma distinta sobre os liderados, além de ter um efeito mais ou menos positivo ou negativo sobre o clima organizacional. $\mathrm{O}$ autor propõe ainda que os líderes mais eficazes são aqueles capazes de adotar diferentes estilos, dependendo da situação em que se encontram. 


\section{Quadro 1 \\ Estilos de liderança}

\begin{tabular}{|c|c|c|c|c|}
\hline $\begin{array}{l}\text { Estilo de } \\
\text { liderança }\end{array}$ & $\begin{array}{l}\text { Como } \\
\text { repercute }\end{array}$ & $\begin{array}{c}\text { Impacto } \\
\text { sobre } \\
\text { o clima }\end{array}$ & $\begin{array}{l}\text { O estilo em } \\
\text { uma frase }\end{array}$ & $\begin{array}{l}\text { Situações em } \\
\text { que é adequado }\end{array}$ \\
\hline $\begin{array}{c}\text { Visionário } \\
\text { (authoritative) }\end{array}$ & $\begin{array}{l}\text { Impele as pessoas rumo a } \\
\text { objetivos compartilhados. }\end{array}$ & $\begin{array}{l}\text { O mais } \\
\text { positivo }\end{array}$ & "Vem comigo". & $\begin{array}{c}\text { Circunstâncias que exigem visão e } \\
\text { direção clara. }\end{array}$ \\
\hline Líder-coach & $\begin{array}{l}\text { Conecta as necessidades } \\
\text { individuais às metas da equipe. }\end{array}$ & Positivo & "Tente isso". & $\begin{array}{l}\text { Para promover o desenvolvimento } \\
\text { dos membros da equipe. }\end{array}$ \\
\hline $\begin{array}{l}\text { Gregário ou } \\
\text { Afiliativo }\end{array}$ & $\begin{array}{l}\text { Cria harmonia e constrói } \\
\text { laços emocionais. }\end{array}$ & Positivo & $\begin{array}{l}\text { "As pessoas } \\
\text { primeiro". }\end{array}$ & $\begin{array}{l}\text { Quando há problemas na equipe } \\
\text { ou em situações estressantes. }\end{array}$ \\
\hline Democrático & $\begin{array}{l}\text { Valoriza as ideias e obtém o } \\
\text { compromisso pela participação. }\end{array}$ & Positivo & $\begin{array}{l}\text { "O que vocês } \\
\text { acham?" }\end{array}$ & $\begin{array}{l}\text { Para construir consenso e obter } \\
\text { apoio de empregados valiosos. }\end{array}$ \\
\hline $\begin{array}{l}\text { Marcador de } \\
\text { ritmo }\end{array}$ & $\begin{array}{c}\text { Fixa metas desafiadoras } \\
\text { e empolgantes. }\end{array}$ & Negativo & $\begin{array}{l}\text { "Faço o que eu } \\
\text { faço, agora". }\end{array}$ & $\begin{array}{l}\text { Para obter resultados rápidos de } \\
\text { um time competente e motivado. }\end{array}$ \\
\hline $\begin{array}{l}\text { Coercitivo ou } \\
\text { Autoritário }\end{array}$ & $\begin{array}{l}\text { Alivia o medo ao dar instruções } \\
\text { claras em uma emergência. }\end{array}$ & Negativo & $\begin{array}{c}\text { "Faça o que eu } \\
\text { digo". }\end{array}$ & Em situações de crise. \\
\hline
\end{tabular}

Fonte: Baseado em Goleman (2000).

\section{Recrutamento e seleção de pessoas}

A gestão de recursos humanos é composta por uma série de funções - incluindo recrutamento e seleção, treinamento e desenvolvimento, avaliação de desempenho, remuneração e recompensa - que têm por objetivo permitir à organização contar com uma força de trabalho qualificada e motivada a contribuir para o alcance de seus objetivos estratégicos (Brito \& Oliveira, 2014; Dessler, 2013).

O recrutamento e seleção são dois processos frequentemente tratados conjuntamente, mas cumprem funções distintas. Enquanto o recrutamento envolve a atração de um conjunto de candidatos para posições a serem ocupadas em uma organização (Breaugh, 2008), a seleção corresponde à escolha do candidato mais adequado a cada posição (Bohlander \& Snell, 2015). Nesse processo de escolha, habitualmente busca-se o candidato com os melhores conhecimentos, habilidades e atitudes necessários ao seu desempenho individual na posição, mas também podem ser considerados fatores como retenção, o desempenho da equipe e os objetivos estratégicos da organização (Ryan \& Ployhart, 2014).

Existem duas abordagens para o recrutamento, que pode ser feito tanto internamente - com pessoas que já fazem parte do corpo de funcionários da organização - quanto externamente (Bohlander \& Snell, 2015; Dessler, 2013). Quando uma organização prioriza o recrutamento interno, são contratadas externamente apenas pessoas para posições na base, enquanto as demais vagas são preenchidas por meio da promoção ou da transferência de empregados de outras áreas. Quando se prioriza o recrutamento externo, buscam-se candidatos de fora da organização para preenchimento das vagas em aberto, quaisquer que sejam elas. Das diversas vantagens associadas ao recrutamento interno, destaca-se a motivação dos empregados por um bom desempenho, considerando que estes podem ser recompensados com uma promoção ou uma movimentação horizontal. Além disso, os empregados também podem se sentir estimulados a investir em sua própria capacitação, dada a perspectiva de promoção ou mudança de função (Bohlander \& Snell, 2015).

O processo de seleção pode ser divido em três etapas. Em primeiro lugar, é necessário mapear o conjunto de conhecimentos, habilidades e atitudes que serão avaliados em cada candidato. Esses fatores dependem da função a ser desempenhada e englobam tanto habilidades cognitivas quanto não cognitivas, incluindo personalidade, inteligência emocional, interesses e integridade (Bohlander \& Snell, 2015; Ryan \& Ployhart, 2014). Em seguida, cada candidato é avaliado em relação aos aspectos identificados na etapa anterior, por meio de diferentes métodos de avaliação. Dentre tais métodos, os mais comuns são os 
testes de habilidades cognitivas, testes de personalidade, testes de integridade e centros de avaliação, além de dinâmicas de grupo e entrevistas pessoais (Bohlander \& Snell, 2015; Dessler, 2013).

Por fim, é necessário tomar a decisão final sobre o candidato mais adequado. Duas abordagens podem ser adotadas, a clínica e a estatística (Bohlander \& Snell, 2015). A abordagem clínica - executada pelos responsáveis pela decisão - envolve uma análise qualitativa e holística de cada candidato. Um risco que se corre com esta abordagem é o da influência de estereótipos e outros vieses comuns na tomada de decisão. A abordagem estatística, por ser mais objetiva, contribui para reduzir tais vieses. Neste caso, os candidatos recebem uma pontuação para cada critério de avaliação e o escolhido é o que obtiver a maior pontuação total. Em termos de critérios, podem ser estabelecidos pesos maiores para aqueles considerados mais importantes e, ainda, valores de corte podem ser criados, de forma que candidatos que não obtiverem pontuação mínima em algum critério sejam desconsiderados (Bohlander \& Snell, 2015).

Ao longo do processo de seleção, Bohlander e Snell (2015) chamam a atenção para alguns aspectos importantes a serem pensados:

- Deve-se se concentrar na adequação do candidato à posição atual ou no seu potencial de progresso na organização?

- Devem ser considerados candidatos com maior qualificação do que o necessário?

- Devem ser considerados candidatos não plenamente capacitados, mas com potencial?

- Como lidar com questões relativas à diversidade?

Com relação a esta última questão, cumpre apontar que a temática da diversidade tem recebido crescente atenção nas organizações, incluindo dimensões como gênero, idade, raça e etnia, orientação sexual, e habilidades físicas e mentais (Nkomo, Bell, Roberts, Joshi \& Thatcher, 2019; Shore et al., 2009). Na próxima seção se discutirá em maior profundidade a diversidade de gênero nas organizações, com destaque para a participação relativamente baixa de mulheres em posições de liderança.

\section{Diversidade de gênero e o teto de vidro}

Muito tem sido discutido sobre a importância da diversidade nas organizações, incluindo a diversidade de gênero (Nkomo et al., 2019; Shore et al., 2009). Estudo conduzido pela McKinsey (2015), por exemplo, destaca a importância das mulheres para a economia dos países. Com relação aos Estados Unidos da América, estima-se que o Produto Interno Bruto (PIB) do país seria $25 \%$ menor caso não tivesse havido uma entrada expressiva de mulheres no mercado de trabalho a partir da década de 1970 (Barsh \& Yee, 2011). Também há evidências de que a diversidade de gênero tem um impacto positivo sobre a gestão das organizações.

Eu sei por experiência própria que a diversidade de gênero leva a um melhor desempenho, uma cultura mais inclusiva e decisões mais equilibradas (Peter Bodin, CEO Global, como citado em Grant Thornton International, 2019, p. 6).

A despeito dessas evidências, as mulheres enfrentam uma série de dificuldades no mercado de trabalho. Em primeiro lugar, frequentemente são segregadas em ocupações menos reconhecidas socialmente. Por exemplo, empregadas domésticas são, em sua maioria, mulheres. Outro exemplo pode ser encontrado na área da saúde, onde as enfermeiras são predominantemente mulheres, enquanto a maioria dos médicos é formada por homens, apesar de essa diferença vir se reduzindo ao longo do tempo (Bruschini, 2007).

Além disso, evidências apontam que as mulheres recebem menos do que os homens, mesmo ocupando posições equivalentes. Este fenômeno é denominado discriminação salarial e ocorre quando "[...] para mesmos níveis de escolaridade, experiência e controlados por outros fatores que teriam impacto na produtividade de ambos os sexos, é observada uma diferença salarial entre os gêneros" (Madalozzo, Martins \& Lico, 2015, p. 1).

Por fim, verifica-se em todo o mundo que as mulheres estão sub-representadas nos escalões superiores das organizações, embora também tenha havido progressos nessa área. Pesquisa global conduzida pela Grant Thornton International (2019) - com 4.812 empresas de 32 países - aponta que apenas $29 \%$ das posições de liderança nas organizações são ocupadas por mulheres, percentual que chega a $34 \%$ no Brasil. 
Outro estudo, envolvendo 532 empresas com sede ou operações no Brasil, mostra que $19 \%$ dos cargos de liderança são ocupados por mulheres. Na medida em que aumenta a importância do cargo, esse percentual decresce, conforme ilustrado na Figura 2 (Talenses-Insper, 2019).

Figura 2

Participação feminina em cargos de liderança

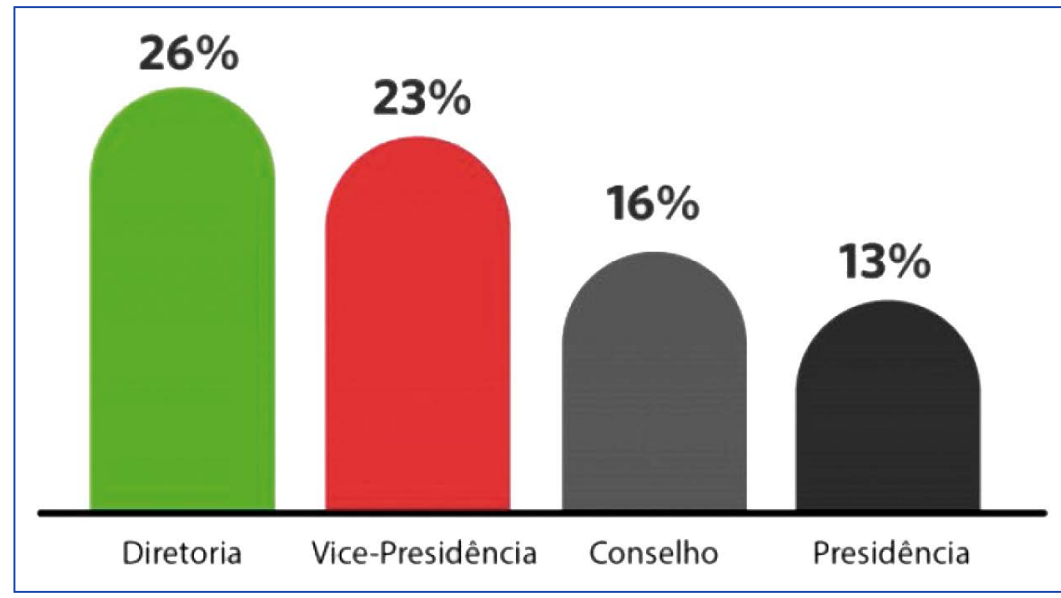

Fonte: Talenses-Insper (2019).

A essa dificuldade de acesso das mulheres a posições de maior responsabilidade e prestígio atribui-se a expressão "teto de vidro" (glass ceiling), entendida como uma barreira importante, mas por vezes imperceptível, que bloquearia o acesso das mulheres aos níveis superiores da hierarquia organizacional (Eagly \& Carli, 2007; Steil, 1997).

Quais fatores explicariam a existência do teto de vidro? Rutherford (2014) chama a atenção para o fato de que a cultura das organizações tem sido construída com base nos interesses dos homens, levando as mulheres a se sentirem como "outsiders". A autora, por exemplo, ressalta que a cultura de uma organização é fortemente influenciada pelo seu passado e que a maior parte delas foi fundada por homens e é predominantemente liderada por homens.

Eagly e Carli (2007) chamam a atenção para quatro aspectos importantes:

- O preconceito contra as mulheres faz com que os homens sejam privilegiados em processos seletivos, mesmo com qualificações equivalentes.

- A resistência à liderança feminina baseada na percepção de que mulheres em posições de liderança são mais egoístas, traiçoeiras e exigentes.

- Dificuldades de definir um estilo próprio de liderança, uma vez que as mulheres se sentem divididas entre um estilo mais agregador (comum às mulheres) e posturas mais assertivas, percebidas como necessárias aos líderes bem-sucedidos.

- Demandas familiares, que frequentemente levam mulheres a interromper suas carreiras ou que dificultam a participação em atividades necessárias ao seu avanço (por exemplo, networking).

Com relação a este último item, outros estudos apontam que muitas mulheres abrem mão de posições mais elevadas na hierarquia das organizações por entenderem que os benefícios não superam as perdas, especialmente em relação aos cuidados e à atenção com a família (Silva \& Rossetto, 2010; Slaughter, 2012).

Além disso, evidências indicam que a percepção do gestor em relação a zonas de conflito entre vida pessoal e vida profissional levam mulheres a serem preteridas em processos de promoção (Hoobler, Wayne \& Lemmon, 2009). O estudo de Brands e Fernandez-Mateo (2017) apontou ainda que a vivência de rejeições em processos seletivos é outro fator que contribui para a sub-representação das mulheres em cargos mais elevados nas organizações.

Em resumo, a literatura nos mostra que o fenômeno do teto de vidro é multifacetado e que sua superação ainda parece longe de ser alcançada, apesar dos importantes avanços observados nos últimos anos. 


\section{REFERÊNCIAS}

Barsh, J., \& Yee, L. (2011, April 01). Unlocking the full potential of women in the US economy. McKinsey \& Company. Recuperado de https://www.mckinsey.com/business-functions/organization/ our-insights/unlocking-the-full-potential-of-women\#

Blanchard, K. (2012). Liderança de alto nível: como criar e liderar organizações de alto desempenho. Porto Alegre, RS: Bookman.

Bohlander, G. W., \& Snell, S. A. (2015). Administração de Recursos Humanos. São Paulo, SP: Cengage Learning.

Brands, R. A., \& Fernandez-Mateo, I. (2017). Leaning out: How negative recruitment experiences shape women's decisions to compete for executive roles. Administrative Science Quarterly, 62(3), 405-442. Recuperado de https://doi.org/10.1177/0001839216682728

Breaugh, J. A. (2008). Employee recruitment: Current knowledge and important areas for future research. Human Resource Management Review, 18(3), 103-118. Recuperado de https://doi.org/10.1016/j. hrmr.2008.07.003

Brito, R. P., \& Oliveira, L. B. (2014). A relação entre gestão de recursos humanos e desempenho organizacional. Brazilian Business Review, 13(3), 94-115. Recuperado de https://doi.org/10.15728/bbr.2016.13.3.5

Bruschini, M. C. A. (2007). Trabalho e gênero no Brasil nos últimos dez anos. Cadernos de Pesquisa, 37, 537-572. Recuperado de https:// doi.org/10.1590/S0100-15742007000300003

Dessler, G. (2013). Human Resource Management (13a ed.). Upper Saddle River, NJ: Pearson Education.

Eagly, A. H., \& Carli, L. L. (2007). Women and the labyrinth of leadership. Harvard Business Review, 85(9), 63-72.

Goleman, D. (2000). Leadership that gets results. Harvard Business Review, 78(2), 4-17.

Grant Thornton International. (2019, March 08). Women in business: construindo um plano de ação. Recuperado de https:// www.grantthornton.com.br/insights/artigos-e-publicacoes/ women-in-business-2019/

Hoobler, J. M., Wayne, S. J., \& Lemmon, G. (2009). Bosses' perceptions of family-work conflict and women's promotability: Glass ceiling effects. Academy of Management Journal, 52(5), 939-957.

Madalozzo, R., Martins, S., Lico, M. R. (2015). Segregação ocupacional e hiato salarial entre os gêneros (Working Paper, n. 357). São Paulo, SP: Insper.
McKinsey. (2015). The power of parity: How advancing women's equality can add \$12 trillion to global growth. New York, NY: McKinsey Global Institute. Recuperado de https://www.mckinsey.com/featuredinsights/employment-and-growthhow-advancing-womens-equalitycan-add-12-trillion-to-global-growth\#

Nkomo, S. M., Bell, M. P., Roberts, L. M., Joshi, A., \& Thatcher, S. M. B. (2019). Diversity at a critical juncture: New theories for a complex phenomenon. Academy of Management Review, 44(3), 498-517. Recuperado de https://doi.org/10.5465/amr.2019.0103

Robbins, S. P., Judge, T. A., \& Sobral, F. (2011). Comportamento organizacional: uma perspectiva brasileira (14a ed.). São Paulo, SP: Pearson.

Rutherford, S. (2014). Gendered organizational cultures, structures and processes: the cultural exclusion of women in organizations. In R. J. Burke \& D. A. Major (Eds.), Gender in Organizations. Cheltenham, UK: Edward Elgar Publishing.

Ryan, A. M., \& Ployhart, R. E. (2014). A Century of Selection. Annual Review of Psychology, 65(1), 693-717. Recuperado de https://doi. org/10.1146/annurev-psych-010213-115134

Shore, L. M., Chung-Herrera, B. G., Dean, M. A., Ehrhart, K. H., Jung, D. I. ... Singh, G. (2009). Diversity in organizations: Where are we now and where are we going? Human Resource Management Review, 19(2), 117-133. Recuperado de https://doi.org/10.1016/j. hrmr.2008.10.004

Silva, A. B., \& Rossetto, C. R. (2010). Os conflitos entre a prática gerencial e as relações em família: uma Abordagem complexa e multidimensional. Revista de Administração Contemporânea, 14(1), 40-60. Recuperado de https://doi.org/10.1590/S1415-65552010000100004

Slaughter, A. M. (2012, July/August). Why women still can't have it all. The Atlantic. Recuperado de https://www.theatlantic.com/ magazine/archive/2012/07/why-women-still-cant-have-it-all/309020/

Steil, A. V. (1997). Organizações, gênero e posição hierárquica: compreendendo o fenômeno do teto de vidro. RAUSP Management Journal, 32(3), 62-69.

Talenses-Insper. (2019). Panorama Mulher 2019 (3a ed.). São Paulo, SP: Talenses Group e Insper. Recuperado de http://online.fliphtml5. com/gbcem/wbwh/\#p=1

Yukl, G. (2013). Leadership in organizations (8a ed.). London, UK: Pearson Education. 
Mestranda em Administração na Faculdades Ibmec-RJ. E-mail: luizawanke@globo.com

Vivian Luiz Coco

ORCID: https://orcid.org/0000-0002-6220-3343

Mestranda em Administração na Faculdades Ibmec-RJ.E-mail: vivian.coco@lickslegal.com

Lucia Barbosa de Oliveira

ORCID: https://orcid.org/0000-0001-7792-5552

Doutora em Administração pelo Instituto Coppead de Administração (Coppead-UFRJ); Professora da Escola Brasileira de Administração Pública e de Empresas (FGV-EBAPE).E-mail: lucia.oliveira@fgv.br

Ana Christina Celano Teixeira ORCID: https://orcid.org/0000-0002-4521-7399

Doutora em Administração pela Escola Brasileira de Administração Pública e de Empresas (FGV-EBAPE); Professora do Mestrado em Administração das Faculdades Ibmec-RJ. E-mail: anacelano@gmail.com 